\title{
A NOTE ON BLOCK VANDERMONDE MATRICES
}

\author{
CHAO XIA
}

Abstract. Motivated by the concept of complete pairs, the concept of an almost complete $l$ tuple of matrices is presented. We show that an almost complete $l$ tuple of matrices can be extended to a complete $l$ tuple of matrices.

Mathematics subject classification (2020): 15A80, 15A03.

Keywords and phrases: Vandermonde matrix, matrix polynomial, almost complete $l$ tuple of matrices.

\section{REFERENCES}

[1] S. CHEN AND C. XIA, Extending an almost complete pair of matrices to a complete triple, The Scientific World Journal 2014, 1 (2014), 1-6.

[2] J. E. DENNIS AND R. P. WeBER, The algebraic theory of matrix polynomials, SIAM Journal on Numerical Analysis 13, 1 (1976), 831-845.

[3] I. Gohberg, M. A. KaAshoek, L. Lerer And L. Rodman, Common multiples and common divisors of matrix polynomials, II, Vandermonde and resultant matrices, Linear and Multilinear Algebra 12, 3 (1982), 159-203.

[4] I. Gohberg, P. Lancaster And L. Rodman, Matrix Polynomials, Academic Press, New York, 1982.

[5] M. G. KREIN AND H. LANGER, On some mathematical principles in linear theory of damped, oscillayions of continua, I, Integral Equations Operator Theory 1, 3 (1978), 364-399.

[6] M. G. KREIN AND H. LANGER, On some mathematical principles in linear theory of damped oscillayions of continua, II, Integral Equations Operator Theory 1, 4 (1978), 539-566.

[7] P. LANCASTER, A fundamental theorem on lambda-matrices with applications, I, Ordinary differential equations with constant coefficients, Linear Algebra and Its Applications 18, 3 (1977), 189-211.

[8] F. MARCOS F AND E. PEREIRA, A fixed point method to compute solvents of matrix polynomials, Mathematica Bohemica 135, 1 (2010), 355-362. 